\title{
Rainwater harvesting potentials for drought mitigation in Tunisia: Water quality monitoring
}

\author{
Fatma Mansouri ${ }^{1,3,}{ }^{*}$, Ines Gasmi ${ }^{2}$, Mohamed Moussa $^{2}$, Mohamed $\mathrm{Ksibi}^{1}$ \\ ${ }^{1}$ National School of Engineers, University of Sfax, Tunisia \\ ${ }^{2}$ Lab. of Eremology and Combating Desertification, Institute of Arid Regions, Medenine, Tunisia \\ ${ }^{3}$ Higher institute of a water science and techniques, Gabes, Tunisia
}

\begin{abstract}
Rainwater is extremely important for the arid regions of Tunisia for a better valorization of this water, the indigenous of these regions decided to build earthen cisterns (Majel and Fesquia) to collect rain water, to satisfy their needs and to have sufficient long-term water reserve in case of prolonged drought. Despite the difficulties faced to access the mountainous regions, a survey was conducted concerning all characteristics of earthen cisterns and their uses. 120 samples of water have been analyzed in the laboratory for their physicochemical parameters such as $\mathrm{pH}$, EC, sodium, chloride, bicarbonate and microbiological quality parameters such as total coliforms, and Escherichia coli. It has been noted that the majority of people $(62 \%)$ used rainwater as drinking water, for animal watering and as supplementary irrigation. In fact, physic-and chemical properties of, the rainwater samples collected are suitable for consumption according to WHO 2017 standards. However, the results of our microbiological indicator analyses suggested that rainwater stored in Majel and Fesquia are not suitable for human consumption without any treatment. Rainwater can be considered as potential source for non-potable uses, such as irrigation. The samples collected were categorized as suitable with regard of SAR belonged to the excellent to good class.
\end{abstract}

\section{Introduction}

In the MENA regions, 15 of 19 countries are below or near the water scarcity level. Nine countries have less than $250 \mathrm{~m}^{3}$ per capita per year, three others have $250-500 \mathrm{~m}^{3}$ [1]. Among these countries, Tunisia is classified to have an arid to semi-arid climate and a shortage of fresh water $[2,3,4]$. In fact, the southern of Tunisia suffers from lack of drinking water and over-exploitation of groundwater. Water is a very important material having vital importance for human and other organisms. It is used for drinking, cleaning, domestic and agricultural purposes [5]. Throughout the history, people have preferred the sites around the sources, where it has been easy to access the water. This issue allowed the local population to find water conservation techniques to meet growing needs such as the earthen cisterns for rain water harvesting known by the names "Majel" and "Fesquia". This is an ancient technique

* Corresponding author: fatmamansouri93@gmail.com 
that dates back over 3000 years. It involves collecting, filtering and storing for irrigation and other purposes such as for drinking. The principal reason for choosing this region is that people live only from this sources of water. In addition, it is a very poor region where people lack of sufficient capacity to do a daily maintenance necessary to protect water cisterns. The main objectives of this work are (i) to evaluate the physico-chemical and microbiological qualities of rainwater in the region of Dkhilet-Toujene which is in the unenviable position of being a city facing the threat of running out of potable water, (ii) to reveal the pollution problems, to determine the suitability level in terms of aquatic life, and (iii) to classify the water in accordance with WHO standards. We are interested to study the different uses of water tanks to show the importance of this water to people to increase crop production and reduces the use of groundwater thus increasing its levels.

\section{Materials and methods}

\subsection{Study area}

The studied area is located in the "berber" village of Dkhilet-Toujene which belong to the delegate of Mereth situated at 25 kilometers the governorate of Gabes in South-East of Tunisia. The studied area is characterized by the presence in the mountains of Matmata and Dahar and connected to the plain of the Djeffara (Figure 1). The habitants from DkhiletToujene collected rain waters in cistern called a Fesquia or Majel, used to provide drinking water for people and animals as well as water for small irrigation purposes by collecting and storing runoff water in reservoirs of varying capacities.

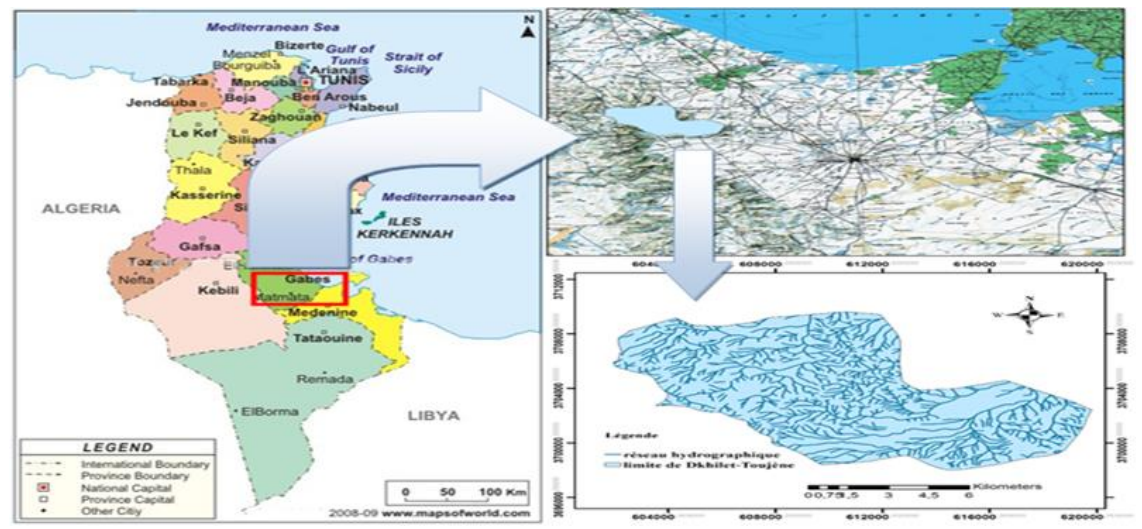

Fig. 1. Localization of the study area

\subsection{Investigation and study area}

The survey was conducted in February 2017 for a cisterns numbred from 1 to 120, in DkhiletToujene, and the surrounding (Toujene and Tounine). The questioner distributed focuses on the capacity and state of the earthen cisterns, the impluvium surface and the different uses of water. Rainwater samples were collected and placed on the roofs of houses in open and carry them in clean plastic containers to ensure that the water have no contact with any object before getting into the container. These samples were analyzed on the same day of collection to preclude chemical reactions that may occur in the samples. The physio-chemical analyses $\left(\mathrm{pH}, \mathrm{EC}, \mathrm{DR}, \mathrm{Na}^{+}, \mathrm{SO}_{4}{ }^{2-}\right.$ and $\mathrm{NO}_{3}{ }^{-} \ldots$ ) and microbiological analyses (TC, E-coli) have been carried out in the laboratory of institute of arid region of Medenine and Gabes following the 
Standard Methods for the Examination of Water and Wastewater, [6] and the guidelines for Drinking-Water Quality [7]. The earthen cisterns require a large catchment area, having small capacity with high construction cost and maintenance. An impluvium is used for collecting rainwater. It is essentially composed of: roof or catchment area; gutter system collecting rainwater, also, conduct draining rainwater to the reservoirs; and water tank or tank for storage of rainwater (Fig. 2).
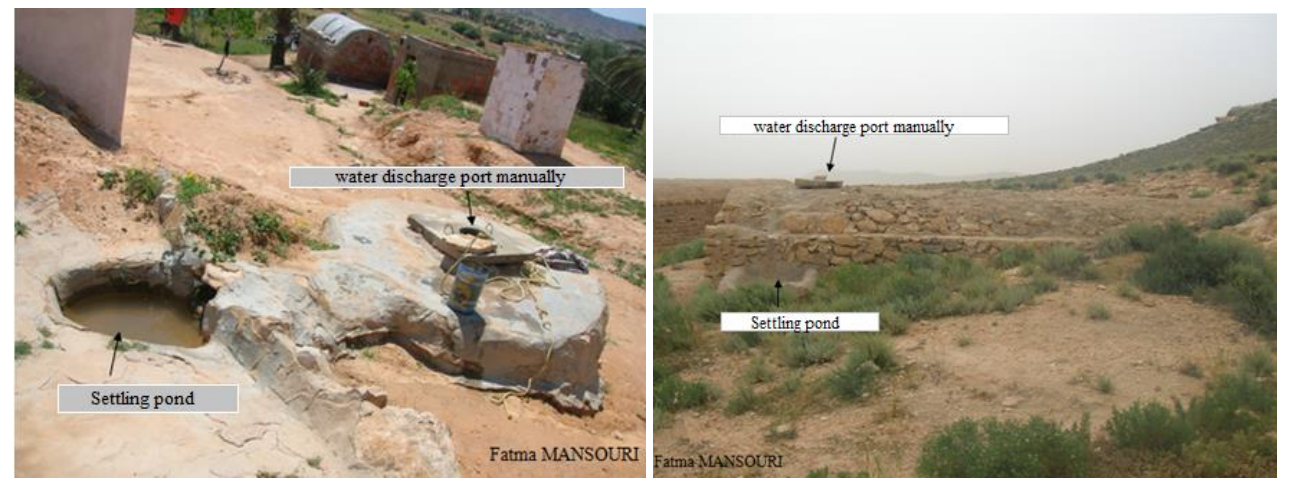

Fig. 2. Majel cistern type (left) and Fesquia cistern type (right)

\section{Results and discussion}

Despite the difficulties to access to the villages, we explored a maximum of earthen cisterns. We have found that most of the cisterns are of 'Majel' type for about $82.5 \%$ and only $17.5 \%$ of cisterns are in the form 'Fesquia'. According to the rural engineers working at regional authority for agricultural and development (RCAD), the cost of construction of the Majel cisterns types is cheaper (100 Dinars for $1 \mathrm{~m}^{3}$ ) than 'Fesquia' cisterns ones (130 Dinards for $1 \mathrm{~m}^{3}$ ). Otherwise, in this study, we have been informed by the indigenous people that the reasons for choosing 'Majel' is principally the low cost of such cisterns compared 'Fesquia' [8]. According to our survey, most of the indigenous $(62 \%)$, using cisterns water for everything such as; drinking, households, irrigation, and animal watering, because they don't have access to potable water. The survey revealed also that water stored in cisterns is used mostly for animal watering; due the dominance of animal husbandry and the lack of other water sources, which requires people to build cisterns to solve the problem of scarcity of water resources.

\subsection{Physic-chemical analysis}

It is not only the storage of water that is important, but it is also necessary to maintain its quality. Hence it is equally important to carry out qualitative and quantitative estimation of different physicochemical parameters such as $\mathrm{pH}, \mathrm{EC}$, sulfate, chloride, nitrates, potassium... used for testing of water quality. In the present study, results obtained for physico-chemical analysis carried out for the 120 cisterns harvested rain-water samples from the three different villages. Results obtained are grouped in the table 1.

The $\mathrm{pH}$ values of rain water samples varies from 6.6 and 10.4. In fact, in general, the $\mathrm{pH}$ of water is slight acid. This is due to the leaching of atmospheric pollutants which affects the chemical composition and $\mathrm{pH}$ of rainwater. The high $\mathrm{pH}$ values were found in cistern number 117 at the village of Dkhilet-Toujene. The electrical conductivity is referred as key factor for determining the purity of water that depends on nature and concentration of ionized substances (chloride, nitrate, sulphate, and phosphate anions or sodium, magnesium, calcium, 
iron, and aluminium cations) in the water at water temperature. The conductivity of rainwater samples ranged between 100 to $1255 \mu \mathrm{S} / \mathrm{cm}$. The minimum conductivity value was found in Tounine whereas the maximum value was found in the sample number 103 at Toujene. It is clear from the value of electrical conductivity of the rainwater samples of Tounine are free from considerable contamination of cations and anions from the atmosphere and can be considered as good water.

Rainwater is a mixed electrolyte that contains various amounts of major and minor ions. Sodium, potassium, magnesium, calcium, chloride, bicarbonate, nitrate and sulphate are the major constituents. The main source of dissolved materials such as $\mathrm{Na}^{+}$and $\mathrm{Cl}^{-}$, in the rainwater is sea salt. When waves split, fine droplets of seawater are injected into the atmosphere. The water evaporates, leaving a solid aerosol particle, which is transported by winds until it is dissolved by rain. This process is responsible for the high concentrations of $\mathrm{Na}^{+}$and $\mathrm{Cl}^{-}$in rainwater. The concentrations of $\mathrm{Na}^{+}$ranged in between 7.12 and $56.54 \mathrm{mg} / \mathrm{L}$ and $\mathrm{Cl}^{-}$concentrations ranged from 21.24 to $251.34 \mathrm{mg} / \mathrm{L}$. For $\mathrm{NO}_{3}{ }^{-}$is derived from plants, agriculture animal waste and fertilizers, and automobile exhausts. It is one of the major nitrogenous contributions to the chemical composition of precipitation. It is present in water with a maximum value of $5.3 \mathrm{mg} / \mathrm{L}$. The sulfate is present rainwater at a very low concentration ranging from 3.34 to $8.67 \mathrm{mg} / \mathrm{L}$ in accordance with WHO guidelines (2017). Moreover, the most important levels of potassium $135.71 \mathrm{mg} / \mathrm{L}$ and $169.50 \mathrm{mg} / \mathrm{L}$ were found in the water of cisterns 100 and 105 respectively from Toujene region which are characterized by earthen impluvium while the low concentration is found in cistern 12 taken from the Tounine region which is characterized by a masonry roof. In conclusion, the physicochemical properties of rainwater stored in the earthen cisterns is generally acceptable in agreement with the WHO standards for drinking water. It remains for us to check it microbiological quality.

Table 1. Results of physic-chemical analysis

\begin{tabular}{|c|c|c|c|}
\hline & Minimum value & Maximum value & WHO standards \\
\hline $\mathrm{pH}$ & 6.60 & 10.90 & $6.5-8.5$ \\
\hline $\mathrm{EC}(\mu \mathrm{S} / \mathrm{cm})$ & 100 & 1255 & 1500 \\
\hline $\mathrm{K}^{+}(\mathrm{mg} / \mathrm{L})$ & 8.14 & 169.50 & 30 \\
\hline $\mathrm{Na}^{+}(\mathrm{mg} / \mathrm{L})$ & 7.12 & 56.54 & 200 \\
\hline $\mathrm{Cl}^{-}(\mathrm{mg} / \mathrm{L})$ & 21.24 & 251.34 & 250 \\
\hline $\mathrm{HCO}_{3}^{-}(\mathrm{mg} / \mathrm{L})$ & 33.60 & 420.03 & 380 \\
\hline $\mathrm{SO}_{4}{ }^{-2}(\mathrm{mg} / \mathrm{L})$ & 3.34 & 8.67 & 250 \\
\hline $\mathrm{NO}_{3}{ }^{-}(\mathrm{mg} / \mathrm{L})$ & 0 & 5.30 & 50 \\
\hline
\end{tabular}

\subsection{Microbiological analysis}

In general, the greatest microbial risks are associated with ingestion of water contaminated with human or animal faeces. Coliforms are classed as faecal indicator organisms due to the presence of rotting vegetation, while bird droppings washed down from the roof could account for E. Coli. During construction of the house and the installation of the rainwater harvesting system, the tank for rainwater collect was left open for long periods of time. This would have allowed for significant contamination to occur. In this study, $91 \%$ of the collected rainwater is contaminated with E. Coli and does not meet the WHO standards. This seems to be very dangerous for the inhabitants of this regions because of the daily using of this water. To reduce this disaster, it is necessary to warn people to disinfect these waters by boiling at least 5 minutes before uses or even stop consuming them.

\subsection{Evaluation of irrigation water quality}


As we have found that rainwater are not suitable for human consumption, we attempt to assess performance of rainwater collected in irrigation scheme using some indicators. Water quality is an important element for the sustainable water use in irrigated agriculture, especially when salinity is expected a big problem in an irrigated agricultural area is to avoided. There is two different criteria for evaluating water quality for irrigation that should be determined.

\subsubsection{Sodium adsorption rate}

The combination for rainwater of the electric conductivity and sodium absorption report (SAR) allows to classify this water according to the Riverside diagram of classification for it use in irrigation (figure 3). The graphic represent the characteristics of 120 rainwater samples showing that they have has low alkalizing power and does not present any risk of salinization. In fact, the large amount of sodium ions in the water affects the permeability of the soil and infiltration problems may occur. This is because the sodium present in the soil in exchangeable form replaces the calcium and magnesium adsorbed on clay particles and causes the dispersion of the soil particles [9].

$$
\mathrm{SAR}=\frac{\mathrm{Na}^{2+}}{\sqrt{\left(\mathrm{Ca}^{2+}+\mathrm{Mg}^{2+}\right) / 2}}
$$

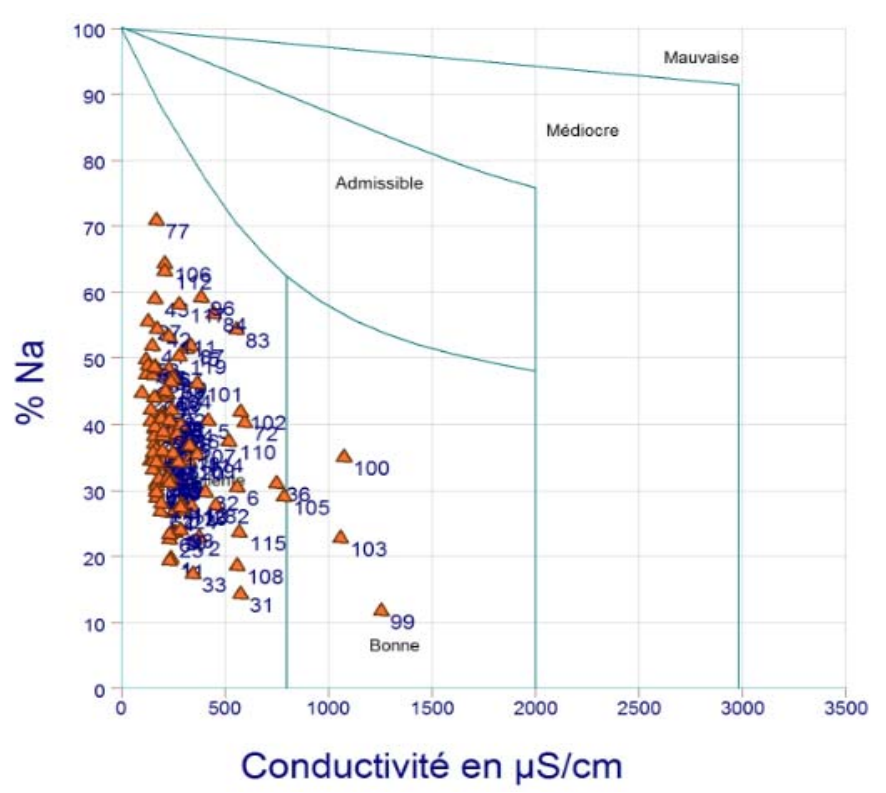

Fig. 4. Riverside diagram

\subsubsection{Percentage of sodium}

Figure 4 shows Wilcox diagram (Wilcox 1955) which is classified into five categories based on sodium percent values. The rainwater samples are mainly of an excellent quality for $75 \%$ excepting the cisterns 99, 100 and 103 which have a high electrical conductivity exceeding $1000 \mu \mathrm{S} / \mathrm{cm}$. Thus so, they characterized by good quality of water for irrigation.

$$
\mathrm{Na} \%=\frac{\left(\mathrm{Na}^{+}+\mathrm{K}^{+}\right) \times \mathbf{1 0 0}}{\mathrm{Ca}^{2+}+\mathrm{Mg}^{2+}+\mathrm{Na}^{+}+\mathrm{K}^{+}}
$$




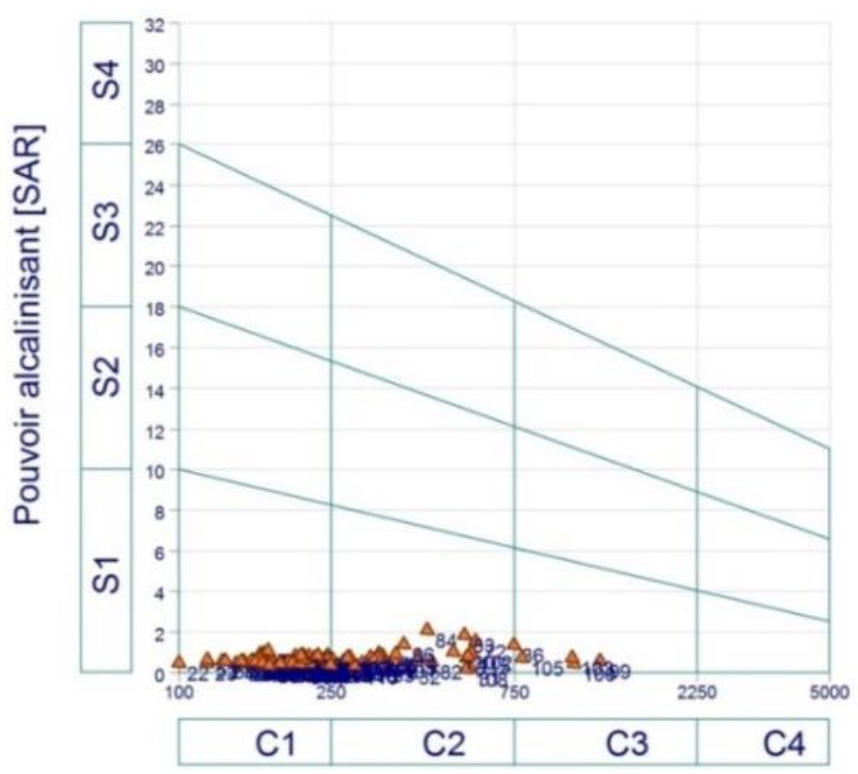

Conductivité en $\mu \mathrm{S} / \mathrm{cm}$

Fig. 4: Percentage of sodium

\section{Conclusion}

Traditional rainwater harvesting techniques in the Mountains of Matmata are characterized by their important role in the storage of runoff water, which represents an important renewable water potential despite the limited water resources. This study looked at the most used techniques in the area; the masonry cisterns roof. The analyses carried out are intended to give an idea on the quality of rainwater stored in the tanks for it best uses. This study highlighted the following points:

- The physico-chemical analysis of the rainwater stored in the cisterns showed an acceptable chemical composition which respects the norm suggested by the WHO except for some cisterns;

- $91 \%$ of the rainwater cisterns has high microbiological contamination. Thus, a disinfection operation is urgent to prevent or at least minimize all kinds of pollution and health diseases; In order to ensure and maintain good water quality, especially for human consumption, it is important that regularly analyze the water for microbiological quality.

- Water quality analyses show that cisterns water can have excellent to good quality for irrigation.

\section{References}

1. PH. Gleick, The world's water 2000-2001: the biennial report on freshwater resources (Island Press, Washington, D.C., USA, 2000)

2. M. Boufaroua, Evolution des techniques de conservation des eaux et des sols en Tunisie, 625-635 (2002) 
3. H. Habaieb, et J. Albergel, Vers une gestion optimale des resources en eau exemple de la Tunisie. Mission IRD de Tunis. P8 Hassan II, 10 p (2001)

4. K. Samir, D. Lassad, Z. Kamel, Hydrological Sciences-Journal-des Sciences Hydrologiques, 51(4), 19 (2006)

5. H. Kaptan, S.T. Özan. S.D.U. Journal of Science, 9 (2), 44-60 (2014)

6. APHA. Standard Methods for the Examination of Water and Wastewater, 20th edn. (American Public Health Association/American Water Works Association/Water Environment Federation, Washington, DC, USA, 1999)

7. WHO. Guidelines for Drinking-Water Quality, 4th edn. (World Health Organization, Geneva, Switzerland, 2017)

8. M. Fetoui, M. Sgaiher, M. Loireau, J.P. Bord, Revue des regions arides, 31(2), 443-450 (2013)

9. B. Agoubi, Caractérisation hydrogéologique et géochimique du système aquifère de la Jeffara maritime: Apport des approches géostatistiques. Thèse doctorat: sciences géologiques (Faculté de science de Sfax, Sfax, 2012) 